\title{
Metacognitive Reading Strategies, Motivation, and Reading Comprehension Performance of Saudi EFL Students
}

\author{
Joel C. Meniado ${ }^{1}$ \\ ${ }^{1}$ ELCY, Royal Commission Yanbu Colleges and Institutes, Yanbu Industrial City, Saudi Arabia \\ Correspondence: Joel C. Meniado, English Language Center, Yanbu Industrial College, P.O. Box 30436, Yanbu \\ Industrial City, Yanbu 41912, Saudi Arabia. Tel: 966-143-928-333. E-mail: meniadoj@rcyci.edu.sa
}

Received: December 29, 2015

Accepted: February 12, 2016 Online Published: February 14, 2016

doi: $10.5539 /$ elt.v9n3p117

URL: http://dx.doi.org/10.5539/elt.v9n3p117

\begin{abstract}
Metacognitive reading strategies and reading motivation play a significant role in enhancing reading comprehension. In an attempt to prove the foregoing claim in a context where there is no strong culture for reading, this study tries to find out if there is indeed a relationship between and among metacognitive reading strategies, reading motivation, and reading comprehension performance. Prior to finding out relationships, the study tried to ascertain the level of awareness and use of metacognitive reading strategies of the respondents when they read English academic texts, their level of motivation and reading interests, and their overall reading performance. Using descriptive survey and descriptive correlational methods with 60 randomly selected Saudi college-level EFL students in an all-male government-owned industrial college in Saudi Arabia, the study found out that the respondents moderately use the different metacognitive reading strategies when reading academic texts. Of the three categories of metacognitive reading strategies, the Problem-Solving Strategies (PROB) is the most frequently used. It was also revealed that the respondents have high motivation to read. They particularly prefer to read humor/comic books. On the level of reading comprehension performance, the respondents performed below average. Using t-test, the study reveals that there is no correlation between metacognitive reading strategies and reading comprehension. There is also no correlation between reading interest/motivation and reading comprehension. However, there is positive correlation between reading strategies and reading motivation. The findings of this study interestingly contradict previous findings of most studies, thus invite more thorough investigation along the same line of inquiry.
\end{abstract}

Keywords: metacognition, metacognitive reading strategy, motivation, reading comprehension, reading interest

\section{Introduction}

Reading Comprehension is one of the most essential study skills in higher education. Academic and even technical courses demand substantial readings, so there is a need for students to be able to comprehend what they read in order to succeed in their academic life and beyond. Unfortunately, in Saudi Arabia like many other countries in the world, reading along with writing is one of the least developed linguistic skills as manifested in Educational Testing Service's (2014) Test of English as a Foreign Language Internet-Based Test (TOEFL iBT ${ }^{\circledR}$ ) and International English Language Testing Service's (2014) IELTS test reports. This can be attributed to students' limited exposure to English reading activities (Alsamadani, 2001) and low interest and motivation to read. Al-Jarf (2007) adds that this can also be due to non-challenging reading instruction; thus, students' cognitive and metacognitive reading abilities are not extensively developed.

With the aim of addressing the aforementioned academic problem in Saudi Arabia, this study was designed to validate previous research findings on the reading comprehension performance of the Saudi EFL students. Further, it also aimed to find out if students are aware of and use different cognitive and metacognitive strategies when they read academic texts. For the purpose of developing appropriate reading programs, instructional strategies, and materials for the students to enhance their ability and willingness to read, this study tried to determine the strategies mostly used and least utilized during the whole reading process, the reading topics the students love to engage in, and their level of motivation to read as well as the reasons behind their reading motivation. Then, the significant relationships among these three sets of data were traced. This study ultimately aimed to prove if awareness and use of metacognitive reading strategies increase reading motivation and if these two factors have direct relationship to reading comprehension performance. While previous studies focused 
more on surveying and determining relationships of two variables - metacognitive reading strategies and reading comprehension, this study tried to include reading interests and motivation. It tried to find out if the three variables interplay and affect one another during the whole reading process.

\subsection{Research Questions}

This study tried to address the following specific questions:

1) What are the metacognitive reading strategies used by the students when reading academic texts? What metacognitive reading strategies do they commonly use?

2) What topics are the students interested in reading about? What is their level of interest / motivation to read?

3) What are the students' reading comprehension levels?

4) Is there a significant relationship between the students' use of metacognitive reading strategies and their reading comprehension performance?

5) Is there a significant relationship between the students' reading interest / motivation and their reading comprehension performance?

6) Is there a significant relationship between the students' use of metacognitive reading strategies and reading interest / motivation?

\subsection{Hypotheses}

The study was also guided by the following hypotheses:

1) There is no significant relationship between the students' use of metacognitive reading strategies and their reading comprehension performance.

2) There is no significant relationship between the students' reading interest / motivation and their reading comprehension performance.

3) There is no significant relationship between the students' use of metacognitive reading strategies and reading interest / motivation.

In an attempt to enrich the existing literature on metacognitive reading strategies, reading motivation, and comprehension performance and to contribute to the development of reading education in Saudi Arabia, this study hopes to fill the gaps using the findings obtained from a specific educational context and perspective.

\section{Literature Review}

\subsection{Reading Comprehension}

Reading comprehension is one of the most essential skills that should be developed and nurtured in a child at home and in school because it is fundamental to success in academic life and beyond. According to Al Noursi (2014), the ability to read for various purposes is a precursor of a successful learning in schools, colleges, and universities. He further notes that it is a survival skill in the $21^{\text {st }}$ century may it be for students or professionals. Dagget and Hasselbring (2007, p. 1), on the other hand, consider reading as 'the key enabler of learning for academic proficiency'. Hence, not being able to develop effective reading can have adverse effects on learning across the curriculum, motivation to read, attitudes toward life, and performances in the workplace.

Reading comprehension is a complex cognitive process. It is explored by educational researchers with its multidimensional components, processes, and factors involved in different settings with the aim of finding better ways of developing it among learners. Theoretically, reading comprehension is an interactive process of deriving meanings from a text (Rumelhart, 1981). Trehearne and Doctorow (2005) support this claim saying that it is an interaction of different variables (reader, text, environment) in a sociocultural context. It is viewed as a complex set of cognitive activities involving many skills and dimensions such as 'the perception of words, clear grasp of meaning, thoughtful reaction, and integration' (Hermosa, 2002, p. 63).

There are different variables or components influencing the reading comprehension performance of students. Some of these are vocabulary knowledge, background knowledge, knowledge of grammar, metacognitive awareness, syntactic knowledge, and reading strategies (Koda, 2005). In addition to the components or variables that shape reading comprehension, there are also other more specific elements or factors that influence one's reading performance. These include students' reading attitudes or motivation, breadth and depth of engagement in reading, effective instruction on comprehension techniques, rich vocabulary and world knowledge, fluency, text structure or genre, opportunities for oral and written expression, and awareness on different reading strategies (Trehearne \& Doctorow, 2005). Perfetti, Landi, and Oakhill (2004) also identified three higher-level 
factors in comprehension: sensitivity to story structure, inference making, and comprehension monitoring. Further, in the study of Geske and Ozola (2008), socio economic factors in the family, collaboration of a student and family, student's reading outside the school, and student's reading at school emerged as significant factors affecting comprehension. Nergis (2013) also found out that depth of vocabulary knowledge, syntactic awareness, and metacognitive awareness have influence on academic reading comprehension.

In the study of Alshumaimeri (2011), he found out that oral reading method positively affects comprehension performance of Saudi students. The study of Mermelstein (2014) also revealed that extensive reading program significantly improves Taiwanese students' reading comprehension levels and performance. The same result was obtained by Erfanpour (2013) with his Iranian students. Examining the effect of technology, Alshumaimeri and Alasmari (2012) found out that using WebQuests improves students' motivation and reading comprehension.

\subsection{Metacognitive Reading Strategies}

Metacognition basically refers to thinking about thinking. According to Flavell (1979), metacognition involves one's knowledge about his thinking processes and products, active monitoring, and regulation of cognitive processing activities. It is categorized into four components: 1) the metacognitive knowledge which refers to the person's awareness or perceptions about the factors (i.e. person, task, strategy) influencing cognitive activities; 2) the metacognitive experiences which refer to the individual's mental or emotional responses pertaining to any cognitive activity; 3 ) the goals / tasks which refer to the purpose or objective of any cognitive undertaking; and 4) the actions / strategies which refer to activities carried out by learners to fulfill their purpose or metacognitive objectives (Iwai, 2011). It has three main aspects: metacognitive knowledge, metacognitive monitoring, and self-regulation and control (Pintrich, Wolters \& Baxter, 2000) and is viewed in two dimensions: 1) the knowledge of cognition which is made up of three factors such as declarative knowledge (abilities and characteristics that affect cognitive processing), procedural knowledge (using or implementing strategies), and conditional knowledge (assessment and reflection on the effectiveness of the strategies used) and 2) the regulation of cognition which includes planning, monitoring, testing, revising, and evaluating strategies used (Iwai, 2011).

Louca (2003) describes metacognition as cognition about cognition because it entails examining the brain's processing during the reading / thinking process. Reading as a cognitive process implies that metacognition or awareness and regulation of one's thinking during the reading process could lead to better comprehension. According to Iwai (2011), metacognition is key to reading comprehension since it is found essential in the development of some linguistic, cognitive, and social skills.

In the field of reading, metacognitive strategies are those activities that make students aware of their thinking as they do reading tasks. The New South Wales Department of Education and Training (2010) defines metacognitive reading strategies as planned, intentional, goal-directed, and future-oriented mental activities and processes that help a reader think about and check how he progresses in fulfilling a cognitive task. In fulfilling a task using metacognition, a learner plans and activates, then monitors, controls, reacts, and reflects (Pintrich, Wolters, \& Baxter, 2000). Iwai (2011) summarizes the process of metacognition in three steps: 1) Planning; 2) Monitoring; and 3) Evaluation.

Metacognitive reading strategy awareness plays an important role in reading comprehension and educational process (Ditzel, 2010; Mytcowicz, Goss, \& Steinberg, 2014; Ahmadi, Ismail, \& Abdulla, 2013). Awareness and use of metacognitive reading strategies have positive and direct relationship with reading comprehension performance; thus, students who use these strategies perform better in reading proficiency tests / courses (Yuksel \& Yuksel, 2012; Pressley, et al., 1998; Ahmadi, Ismail, \& Abdullah, 2013; Al-Sobhani, 2013; Tavakoli; 2014; Magogwe, 2013; Hong-Nam, 2014; Zhang \& Seepho, 2013; Memis \& Bozkurt, 2013; Phakiti, 2006; Kummin \& Rahman, 2010). Therefore, learning metacognitive reading strategy skills can be one solution to the problem of poor reading comprehension, hence, the need for it to be developed and emphasized in the EFL teaching and learning processes.

In the study of Estacio (2013), it was revealed that the use of the metacognitive reading strategies is a predictor of reading comprehension test scores. Ilustre (2011) also investigated if metacognitive reading strategies are better predictor of text comprehension and she found out that Problem Solving Strategies correlated positively with reading comprehension.

Ismail and Tawalbeh (2015) conducted a quasi-experimental study examining the effect of the metacognitive reading strategies on EFL low achievers in reading. The study revealed that training on the use of metacognitive strategies among low achieving EFL readers improves reading comprehension performance. Sen (2009) also conducted a similar study in Turkey. His study revealed the potential of metacognitive reading strategies in 
developing effective and successful readers. Royanto (2012) also examined the effectiveness of an intervention program based on scaffolding to improve metacognitive strategies in reading. She found out that the program activated unused metacognitive strategies, leading to the conclusion that the learners have the metaknowledge.

While most studies found positive correlations and effects of metacognitive strategies on reading comprehension, some found quite the opposite. In Indonesia, Pammu, Amir and Maasum (2014) found out that Indonesian EFL learners use different metacognitive reading strategies but their use of metacognitive reading strategies did not bring corresponding improvements in the observed reading performances. In Russia, Korotaeva (2012) examined the metacognitive strategies in reading comprehension of education majors and found out that the respondents exhibited extremely ineffective metacognitive strategy use.

Alsamadani (2009) explored the frequency and type of metacognitive reading strategies used by the Saudi EFL college-level students and correlated them to their EFL reading performance. He found out that Saudis more frequently use planning strategies than attending and evaluating strategies. He also found out that the students' use of metacognitive reading strategies does not influence their comprehension level. Also, in the study of Pei (2014), it was revealed that metacognitive reading instruction did not result in better reading comprehension performance of Chinese students. Mehrdad, Ahghar, and Ahghar (2012) also found out that use of cognitive and metacognitive instruction does not always have a positive effect on the EFL students' reading comprehension performance.

\subsection{Reading Interest / Motivation}

Hermosa (2002) implicitly defines reading motivation as the interest or desire to read for different reasons or purposes. She believes that positive reinforcements have favorable effects towards motivation in reading; hence, it is a must that teachers design motivating and engaging reading activities for learners to develop the real love and passion for reading. Baker, Dreher, and Guthrie (2000) suggest that for students to be motivated to read, teachers and parents alike must provide children good foundation at the word level, serve as guide on the side, provide opportunities to read to learn with sufficient interesting reading materials, create a sharing community of learners, make learning contexts stress-free and fun, identify specific child's strengths and weaknesses, provide ample time to read, coordinate with other teachers and administrators for a wholistic reading program, partner with parents, and learn the strategies for engaging and fruitful learning.

Komiyama (2013) examined the factors underlying second language reading motivation of adult English for Academic Purposes (EAP) students. She found that adult EAP students' L2 reading motivation is comprised of both extrinsic and intrinsic factors, confirming the multidimensional nature of reading motivation. Jafari and Shokrpour (2012) also investigated the EAP students' reading motivation of English academic expository texts in Iran. They found out that there is a significant and positive relationship between reading motivation and reading proficiency.

Ahmadi, Ismail, and Abdullah (2013) examined the relationship between students' reading motivation and reading comprehension in the Malaysian context with inclusion of expanded motivational multiplicity as the scope of investigation in order to come up with broader identification of reading comprehension growth predictors. In their study they included motivation constructs (interest, perceived control, collaboration, involvement, efficacy), text genres, specific versus general contexts, and the self versus other evidence sources about motivation as multiple components under investigation. Using qualitative research, they found out that reading motivation has a positive impact on reading comprehension. Students with higher motivation can score higher in reading comprehension tests.

In Saudi Arabia, the level of reading motivation of students is low. In the study of Alsamadani (2001), he revealed that $50 \%$ of his respondents mentioned that they do not read unless it is required. Al-Nujaidi (cited in Alsamadani, 2001) also found out in his study that extensive reading among Saudi EFL learners is an unpopular activity and that they do not voluntarily read English materials outside the class.

The problem on low level of reading motivation is a universal problem (Pitcher et al., 2007). Pitcher et al. (2007) tried to assess the adolescents' motivation to read and the cause of a decline through a descriptive survey method. Findings revealed that students' motivation to read decline because of the mismatch between what they are asked to read and their preferences. With this, the study concluded that matching students' preferred reading materials and instructional strategies would lead to increased motivation and probably improve reading performance. They recommended that teachers must be sensitive to students' purposes and interests.

In a study conducted by Al-Nafisah and Al-Shorman (2011), they investigated the Saudi EFL teacher-college students' reading interests in English, their difficulties in reading, the persons and factors that affect their reading 
behaviors. Using quantitative research, they found out that students are very much interested to read stories, novels, and plays covering such topics as adventures, religion, technology, current events, computers, and sports. However, they have such problems as inaccessibility of the library and other reading materials, time constraints, negative beliefs and attitudes towards reading, and lack of reading support from the family.

\section{Method}

\subsection{Research Design}

Since this study aimed to describe the characteristics and condition of a certain group at a specific time and investigate the relationships of different variables, the descriptive research design was used (Mitchel \& Jolley, 2013; Key, 1997). To determine the metacognitive reading strategies used by the respondents, their reading interest and motivation, and their existing level of reading comprehension performance, the descriptive survey method was utilized. On the other hand, to establish relationships among the three main variables (metacognitive strategies used, reading motivation and interest, and comprehension performance), the descriptive correlational method was employed. In the first phase of the study, the respondents were selected randomly and were asked to answer a set of two (2) questionnaires and a test. In the second phase, the data gathered were tabulated and correlated using a statistical tool (t-test).

\subsection{Sample}

The respondents of the study were 60 randomly selected students from different sections. However, due to absence of some of the selected respondents at any day during the three (3) separate data gathering sessions, only 43 completed the three (3) sets of questionnaires. Thus, only 43 were considered for data analysis. The respondents were all at the same level (Beginner Level, A2 in the CEFR Framework) taking up ENG 001 (General English) Course in the Preparatory Year Program of a government all-male industrial college in Saudi Arabia. Random sampling was utilized in selecting respondents from 22 sections. Considering logistics and time constraints, the researcher decided to take ten percent $(10 \%)$ of the total population as minimum sample requirement.

\subsection{Instruments}

To answer the questions What are the metacognitive reading strategies used by the respondents when reading academic texts? and What metacognitive reading strategies are commonly used?, the Survey of Reading Strategies (SORS) developed by Kouider Mokhtari and Ravi Sheorey (2002) was conducted. A permission to use the questionnaire was sought and granted by the authors. The inventory is composed of 30 questions scaled from 1 to 5,1 being the lowest and 5 being the highest. Below each item is the corresponding Arabic translation to ensure full understanding of the respondents. Scoring and interpreting guidelines are provided by the developers.

The questions What topics are the students interested to read about? and What is their level of motivation to read? were answered through a researcher-made inventory composed of 42 items scaled from 1 to 5,5 being the highest and 1 being the lowest. The items mainly asked the perceptions of the respondents on their topics of interest in reading, their preferences, as well as their beliefs reflecting their motivations in reading. The items were also translated in Arabic to ensure full understanding of the respondents. The completed responses were analyzed using the 5-Point Likert Scale.

The question What are the respondents' level of reading comprehension? was answered by a reading comprehension test developed by the National Center for Assessment in Higher Education (2011) in Saudi Arabia, also locally known as QIYAS. The reading test is a component of the Standardized Test of English Proficiency (STEP). The STEP test, designed to test an individual's proficiency level in the use of English, has four (4) parts: Reading Comprehension (40\%); Structure (30\%); Listening Comprehension (20\%); and Compositional Analysis (10\%). The Reading Comprehension is a 40-item multiple choice test. The test used in this study is the Mock Test conducted by the English Language Center where the researcher works.

\subsection{Data Collection}

The data gathering procedure started with seeking help from the researcher's co-teachers in floating the questionnaires in their respective sections. Upon acceptance, the survey on metacognitive reading strategies and reading motivation were administered to randomly selected students in their respective sections. Subsequently, the reading comprehension test was administered to the same participants who previously answered the first two sets of survey questionnaires. Data gathered were analyzed using descriptive and inferential statistics.

\subsection{Data Analysis}

The survey results on Reading Strategies and Reading Interests / Motivation were scored and analyzed using a 
5-point Likert Scale, Weighted Mean, Standard Deviation, and Ranking. The Reading Comprehension Test was scored based on the QIYAS' scoring system. The relationships between the use of metacognitive reading strategies and reading comprehension performance, reading motivation and reading comprehension performance, and use of metacognitive reading strategies and reading interests / motivation were analyzed using correlation analysis. Specifically, the t-test was used in analyzing correlation because there was no standard deviation for the population.

\section{Results}

\subsection{What Are the Metacognitive Reading Strategies Used by the Students When Reading Academic Texts?}

The use of metacognitive reading strategies of the respondents was surveyed using the Survey of Reading Strategies (SORS) questionnaire developed by Mohktari and Sheorey (2002). The items were categorized into three (3) sub-categories: Global Reading Strategies (GLOB), Problem-Solving Strategies (PROB), and Support Reading Strategies (SUP). Results reveal that in general the students moderately use metacognitive reading strategies when they read academic texts. Among the most commonly used metacognitive strategies are: trying to get back on track when concentration is lost (PROB) with a mean of 3.97 (high), followed by translating from English to the native language (SUP) with a mean of 3.88 (high), and thinking about what is known (activating schema) with a mean of 3.82 (high). The least used strategies on the other hand are using tables, figures, and pictures in text to increase understanding (GLOB) and critically analyzing and evaluating the information presented in the text (GLOB) with a mean of 2.68 (medium). When the strategies are grouped according to categories, the Problem-Solving Strategies (PROB) is the highest with the weighted mean of 3.55 (High), followed by Support Reading Strategies (SUP) with 3.43 (Medium) and Global Reading Strategies (GLOB) with 3.15 (Medium).

\subsection{What Topics Are the Students Interested in Reading about? What Is Their Level of Interest and Motivation to Read?}

Using questionnaire and interview, the study found out that the respondents have utmost preference for reading about humor / comic books with a mean of 4.24 (high), followed by their belief that reading is important to become successful and their practice that when they read something interesting they share it with others both with a mean of 4.22 (high). When the responses were grouped according to respondent, the overall average of respondents' reading interest is 3.27 (medium / moderate).

\subsection{What Are the Students' Reading Comprehension Levels?}

Based on the results of the reading comprehension test as part of the mock STEP test given by the school, the average mean of the scores of the respondents was 32.83. The leveling was made using percentage scores of 50.00 to 60.00 as the average. Hence, below 50.00 was considered below average and above 60.00 as above average. Based on this categorization, it was found out that majority of the respondents fall under below average. The overall average mean of 32.83 (Below Average) further indicates that most of the respondents did not perform well in the reading comprehension test.

4.4 Is There a Significant Relationship Between the Students' Use of Metacognitive Reading Strategies and Their Reading Comprehension Performance?

Table 1. T-test results for the correlation of the respondents' use of metacognitive reading strategies and reading comprehension performance

\begin{tabular}{|c|c|c|c|c|c|c|c|c|}
\hline Variable & $\mathrm{N}$ & Mean & SD & $\mathrm{R}$ & $\mathrm{T}$ & $\overline{\mathrm{Df}}$ & $\bar{P}$ & Decision \\
\hline $\begin{array}{l}\text { Metacognitive } \\
\text { Reading Strategies }\end{array}$ & 45 & 3.328 & 0.566 & -0.073 & -0.47 & 43 & 0.01 & $H_{0}$ not rejected* \\
\hline $\begin{array}{l}\text { Reading } \\
\text { Comprehension } \\
\text { Performance }\end{array}$ & 45 & 32.833 & 13.595 & & & & & \\
\hline
\end{tabular}

Note. ${ }^{*}$ Using $\mathrm{t}<-2.4173$ or $\mathrm{t}>2.4173$ as parameter of rejection.

Table 1 shows the mean and Standard Deviation values of the metacognitive reading strategies and the reading comprehension performance variables. Using correlation coefficient $(r)$ of -0.073 and a significance level of 0.01 , the calculated t- value was -0.47 ; hence, the null hypothesis number $1\left(H_{01}\right)$ was not rejected. This means that 
there is no correlation between the metacognitive reading strategies and reading comprehension.

4.5 Is There a Significant Relationship between the Students' Reading Interest / Motivation and Their Reading Comprehension Performance?

Table 2. T-test results for the correlation of the respondents' reading interests and reading comprehension performance

\begin{tabular}{lllllllll}
\hline Variable & $\mathrm{N}$ & Mean & $\mathrm{SD}$ & $\mathrm{r}$ & $\mathrm{T}$ & $\mathrm{Df}$ & $\mathrm{p}$ & decision \\
\hline Reading Interest & 45 & 3.265 & 0.479 & -0.135 & -0.893 & 43 & 0.01 & $H_{0}$ not rejected* \\
$\begin{array}{l}\text { Reading } \\
\text { Comprehension }\end{array}$ & 45 & 32.833 & 13.595 & & & & & \\
Performance & & & & & & & & \\
\hline
\end{tabular}

Note. *Using $\mathrm{t}<-2.4173$ or $\mathrm{t}>2.4173$ as parameter of rejection.

Table 2 reflects the mean and Standard Deviation values of the reading interest and the reading comprehension performance variables. With a correlation coefficient $(r)$ value of -0.135 and a level of significance at 0.01 , the calculated t-value is -0.893 . Hence, the null hypothesis number $2\left(H_{02}\right)$ is not rejected. It can be said, therefore, that there is no correlation between reading interest and reading comprehension.

4.6 Is There a Significant Relationship Between the Students' Use of Metacognitive Reading Strategies and Reading Interest / Motivation?

Table 3. T-test results for the correlation of the respondents' use of metacognitive reading strategies and reading interests

\begin{tabular}{lllllllll}
\hline Variable & $\mathrm{N}$ & Mean & $\mathrm{SD}$ & $\mathrm{r}$ & $\mathrm{T}$ & $\mathrm{Df}$ & $\mathrm{P}$ & Decision \\
\hline $\begin{array}{l}\text { Metacognitive } \\
\text { Reading Strategies }\end{array}$ & 45 & 3.328 & 0.566 & 0.374 & 2.64 & 43 & 0.01 & $H_{0}$ rejected* \\
Reading Interest & 45 & 3.265 & 0.479 & & & & & \\
\hline
\end{tabular}

Note. *Using $\mathrm{t}<-2.4173$ or $\mathrm{t}>2.4173$ as parameter of rejection.

Table 3 gleans the mean and Standard Deviation values of the metacognitive reading strategies and the reading interest variables. Using the correlation coefficient $(r)$ value of 0.374 at 0.01 level of significance, the calculated $\mathrm{t}$-value is 2.64 , hence, the null hypothesis is rejected. This means that there is a positive correlation between the metacognitive reading strategies and reading interest.

\section{Discussion}

As reflected in the findings, it can be inferred that the different metacognitive reading strategies are moderately used by the respondents when reading academic texts. The moderate use can be attributed to non-familiarity of the students with the existence of some metacognitive reading strategies that could help them comprehend texts. It could also be that teachers are not aware of these strategies, hence, not using them in their reading instruction. This result supports the general findings of Tavakoli (2014), Alsamadani (2009), Yuksel and Yuksel (2012) on Iranian, Saudi, and Turkish EFL students' (respectively) moderate awareness and use of metacognitive reading strategies. It also supports the findings of Hong-Nam and Page (2014) on the moderate use of metacognitive reading strategies of ELLs in America. However, this particular result of the study does not coincide with the general findings of previous researches showing active (High) overall use of metacognitive reading strategies by EFL students in Yemen (Al-Sobhani, 2013) and by those ESL students in Malaysia (Pammu, Amir, \& Maasum, 2014; Maasum \& Maarof, 2012) and in Botswana (Magogwe, 2013). This finding suggests that use of metacognitive strategies vary depending on language learners' settings and orientations. The respondents of Al-Sobhani (2013), Pammu, Amir, and Maasum (2014), Maasum and Maarof (2012), and Mogogwe (2013) are from intermediate level university students with more exposure to the English language. Hence, it is expected that they have lesser language and learning barriers as compared to the respondents of the current study. As university students in an ESL environment, the respondents in the cited studies tend to be more mature learners 
and more aware and able to use different strategies to survive academic reading texts than the respondents of the current study who are purely beginners in an EFL context.

When the metacognitive reading strategies are grouped according to sub-categories, the study revealed that their most frequently used or preferred strategies are those that fall under the Problem Solving Strategies (PROB). Considering the linguistic difficulties of the respondents, they really have to find strategies that help them unlock the barriers (problems) in comprehending a text. This result supports the findings of Al-Sobhani (2013) and Yuksel and Yuksel (2012) having EFL students in Yemen and Turkey actively use Problem Solving Strategies (PROB) at a high level. In ESL contexts, the results also show that even ESL students in Botswana (Magogwe, 2013), in USA (Hong-Nam \& Page, 2014), Indonesia (Pammu, Amir, \& Maasum, 2014), and in Malaysia (Maasum \& Maarof, 2012) use Problem Solving Strategies at a high level. This shows that Problem-Solving Strategies are widely and actively used by different levels of learners in different contexts.

In terms of reading interest and motivation, the respondents prefer to read humorous / comic books. These data mean that the respondents long for fun through reading (in classroom). Overall, the respondents' reading interest and motivation had a general weighted mean of 3.27 (medium). This result goes with Alsamadani's (2001) findings revealing that Saudi student's motivation is not too high and not too low. In his study, he revealed that while some are intrinsically motivated to read, others are not unless it is required. While the findings of this study reveal that students like to read for fun, Al-Nujaidi (in Alsamadani, 2001) claims that reading for pleasure outside the classroom is still an unpopular activity in Saudi Arabia. The result also partly agrees with the findings of Al-Nafisah and Al-Shorman (2011) on Saudi EFL students' reading interests. They found out in their study that Saudi students' top choices on reading materials include adventure, religion, computer, internet, technology, sports, current events, novels, poetry, and plays. Their study suggests that Saudi students have wide array of reading interests and that they differ depending on their individual preferences and contexts. However, these interests have pedagogical implications that need to be addressed in program planning, curriculum development, and instruction.

On reading comprehension performance, the study revealed that the respondents performed below average. It means that most of the respondents did not perform well in the reading comprehension test. The finding supports the published results of the TOEFL iBT tests conducted in 2014 where examinees from Saudi Arabia scored in reading an average of 13 out of 30 and IELTS in 2013 were examinees scored 3.5 (GT) and 4.8 (Academic) out of 9 . Looking at the result, it seems that moderate use of metacognitive reading strategies when reading academic texts does not result in a desirable reading comprehension performance.

To determine the relationship between students' use of metacognitive reading strategies and reading comprehension performance, a t-test analysis was carried out. Based on the results, there is no correlation between the use of metacognitive reading strategies and reading comprehension. Previous studies show that when readers employ metacognitive reading strategies, they perform better in reading. Unfortunately, this did not happen in the current study. Despite the respondents' reported use of metacognitive reading strategies, their reading comprehension performance was still below average. The above finding confirms the findings of Alsamadi (2009) showing no significant relationship between Saudi EFL learners' comprehension performance and their use of reading strategies. It also affirms the findings of Mehrdad, Ahghar, and Ahghar (2012) revealing that use of metacognitive reading strategies has no significant relationship on the reading comprehension performance of elementary and advanced level Iranian EFL students. Lastly, it backs up the findings of Pei (2014) revealing that use of metacognitive reading strategies after a training intervention does not in any way affect reading comprehension performance of Chinese students.

The current study is one of the few studies disproving the findings of previous studies showing positive relationship between metacognitive reading strategies and reading comprehension performance. This could be due to the respondents' tendency to rate themselves high in the metacognitive reading strategies inventory while having limited linguistic skills that can negatively affect their reading comprehension performance. As Alsamadani (2009) mentioned in his study, the awareness and use of metacognitive reading strategies do not guarantee satisfactory reading comprehension performance as there are still many other factors interplaying during the reading process that could affect the overall comprehension performance. Mehrdad, Ahghar, and Ahghar (2012) also explained that the effect of use of metacognitive reading strategies on reading comprehension vary depending on the reader's existing linguistic knowledge, hence, there is no uniform pattern of findings. On the case of the respondents of this study who are still at the beginner level of the English language, the use of metacognitive strategies may not have a more significant effect as mastering linguistic knowledge in English can be more important at their particular level than using metacognitive strategies in comprehending lengthy academic texts. 
This study also found out that there is no correlation between reading interest and reading comprehension. It partly agrees with the findings of Blay, Mercado, and Villacorta (2009) who found out out that not all aspects of motivation have positive relationship with reading comprehension. However, in the study of Ahmadi, Ismail, and Abdullah (2013) investigating the relationship between students' reading motivation and reading comprehension, they found out that reading motivation had a significantly positive effect on the English reading comprehension. The same result is shared by Guthrie, et al. (2006) claiming that reading motivation enhances reading comprehension. The finding of this study is quite unique that it refutes findings of most previous studies. This can be attributed to students' limited linguistic ability and context during the administration of the reading test. In the context of the respondents, as observed in classroom, when they encounter lengthy and difficult academic reading texts, they feel lazy that they just skip the reading text and jump to the question part and guess the correct answer from the choices without even reading and understanding the questions as well as the choices. They just randomly circle the letter of their answer. While the respondents may have moderate level of motivation, they can still perform unsatisfactorily (below average) in reading comprehension due to some other reader, text, and context factors.

On the relationship between reading interest / motivation and use of metacognitive reading strategies, the study found out that there is a positive correlation between the two. This result affirms the findings of Jamshidi and Moghaddam (2013) claiming that Iranian EFL learners' awareness of reading comprehension strategies and reading motivation are positively related. Pierce (2003) explains that metacognition affects motivation in terms of attribution and self-efficacy. Metacognition develops among readers the tendency to attribute their success (or failure) to their ability and effort. Their awareness of what works and doesn't work in the whole reading process makes them confident in their ability to devise strategies or techniques in solving unfamiliar and difficult tasks in the whole reading process.

\section{Conclusion}

Based on the findings of the study, it can be concluded that the respondents are strategic readers employing moderate use of metacognitive reading strategies. Though they are able to moderately plan, monitor, and evaluate their reading performance when reading an academic text, there seems to be an imperative need to integrate explicit instruction of metacognitive reading strategies in the classroom. Having the Problem Solving Strategies (PROB) as the most frequently used strategies, it means that they can deal with any difficulty they encounter in reading a text. This characteristic influences reading interest and motivation as well as confidence and persistence in managing a challenging reading task.

The respondents are very much interested in any reading material that is with humor, fun, enjoyment, and pleasure. This means that they prefer reading for entertainment purposes to education purposes. This implies that teachers need to integrate fun in reading instruction. Implementation of Extensive Reading Program can be viable approach to shift from learning to read to reading to learn with fun. With regards to their motivation to read, the students seem to have a right perspective in reading as they recognize its value as essential to success. This could be a good benchmark to develop in them the ability and willingness to read.

Despite the self-reported use of metacognitive reading strategies in reading academic texts, the respondents are still below average in comprehending academic reading text. This performance can be attributed to the result of the previous research question showing the respondents' strong liking of fun and enjoyable reading materials over at times lengthy and boring academic texts. The low reading comprehension performance of the respondents may also imply that teachers and researchers do not have to focus only on instructing metacognitive strategies to improve reading comprehension performance. Instead, they also have to look into other cognitive, psychological, social, and linguistic factors affecting students' performance and do the necessary interventions.

On proving the hypotheses of this study within its context, it can be concluded that there exists a relationship between the students' use of metacognitive reading strategies and reading motivation. This means that the students' ability to use metacognitive reading strategies can develop or enhance their motivation to read. In the same way, when students are highly motivated to read, the more they are explorative and persistent in using variety of metacognitive reading strategies. However, there is no significant relationship between the students' use of metacognitive reading strategies and their reading comprehension performance. This means that the use of metacognitive reading strategies does not positively affect the reading comprehension performance of the students. This clearly shows that awareness and use of metacognitive reading strategies are not the only factors influencing favorable performance in reading comprehension. There are still many other factors that need to be explored and considered. Lastly, there is no significant relationship between reading interest/motivation and reading comprehension performance. While in other studies motivation plays a great role in reading 
comprehension, this study explains that reading motivation does not always guarantee a favorable reading performance. No matter how highly motivated a person is if he does not have the necessary schematic and linguistic knowledge to actualize the reading task, he will still fail to meet the desired performance level.

\section{Acknowledgments}

The researcher wishes to thank Dr. Kouider Mokhtari of The University of Texas at Tyler for personally allowing him to use the Survey of Reading Strategies (SORS) Questionnaire in this study. The Department of Language Testing of the National Center for Assessment in Higher Education (Saudi Arabia) is also gratefully acknowledged for the Reading Comprehension Test / STEP Test used in the study.

\section{References}

Ahmadi, R. A., Ismail, H. N., \& Abdullah, M. K. (2013). The importance of metacognitive reading strategy awareness in reading comprehension. English Language Teaching, 6(10), 235-249. http://dx.doi.org/10.5539/elt.v6n10p235

Ahmadi, R. A., Ismail, H. N., \& Abdullah, M. K. (2013). The relationship between students' reading motivation and reading comprehension. Journal of Education and Practice, 4(18), 8-17.

Al-Jarf, R. (2007). Developing reading and literacy in Saudi Arabia. Retrieved from http://files.eric.ed.gov/fulltext/ED497944.pdf

Al-Nafisah, K. and Al-Shorman, R. A. (2011). Saudi EFL students' reading interests. Journal of King Saud University - Languages and Translation, 23, 1-9. http://dx.doi.org/10.1016/j.jksult.2009.07.001

Al-Shumaimeri, Y. A. N. (2013). Gender differences in reading comprehension performance in relation to content familiarity of gender-neutral texts. Retrieved from http://faculty.ksu.edu.sa/yousif/Publications/ Microsoft\%20 Word\%20-\%20Gender\%20Differences\%20in\%20 Reading\%20Comprehension.pdf

Alsamadani, H. A. (2011). Saudi students' awareness of reading strategies and factors affecting their EFL reading comprehension. British Journal of Arts and Social Sciences. Retrieved from www.bjournal.co.uk /paper/BJASS_2_2/BJASS_02_02_01.pdf

Alsamadani, H. A. (2009). The relationship between Saudi EFL college-level students' use of reading strategies and their EFL reading comprehension. Retrieved from https://etd.ohiolink.edu/rws_etd/document/get/ ohiou12 24685570/inline

Alshumaimeri, Y. (2011). The effects of reading method on the comprehension performance of Saudi EFL students. International Electronic Journal of Elementary Education, 4(1), 185-195.

Alshumaimeri, Y. A., \& Alasmari, M. M. (2012).The effects of using webquests on reading comprehension performance of Saudi EFL students. TOJET: The Turkish Online Journal of Educational Technology, 11(4), 295-306.

Al-Sobhani, Y. A. (2013). Metacognitive reading strategies use by Yemeni EFL undergraduate university students. Frontiers of Language and Teaching, 4, 121-130.

Baker, L., Dreher, M. J., \& Guthrie, J. T. (eds.) (2000). Engaging young readers: promoting achievement and motivation. New York: Guilford Press.

Blay, R., Mercado, K. A., \& Villacorta, J. (2009). The relationship between motivation and second language reading comprehension among fourth grade Filipino students. Philippine ESL Journal, 2, 5-30.

British Council. (2015). Teaching English: EFL. Retrieved from www.teachingenglish.org.uk/ knowledgedatabase/efl

Dagget, W., \& Hasselbring, T. (2007). What we know about adolescent reading. International Center for Leadership in Education. Retrieved from http://www.leadered.com/pdf/what_we_know_about_adolesent_ reading_2014. pdf

Day, R., \&Bamford, J. (2002). Top ten principles for teaching extensive reading. Reading in a Foreign Language, $14,136-141$.

Ditzel, S. N. (2010). Metacognitive reading strategies can improve self-regulation. Journal of College Reading and Learning, 40(2), 45-63. http://dx.doi.org/10.1080/10790195.2010.10850330

Educational Testing Service (ETS). (2015). Test and Score Data Summary for TOEFL iBT Tests: January 2014 December 2014 Test Data. New Jersey, USA: ETS. Retrieved from https://www.ets.org/s/toefl/pdf/ 94227_unlweb.pdf 
Erfanpour, M. A. (2013). The effect of intensive and extensive reading strategies on reading comprehension: A case of Iranian high school students. English for Specific Purposes World, 14, 1-7.

Estacio, M. J. M. (2013).Bilingual readers' metacognitive strategies as predictors of reading comprehension. Philippine ESL Journal, 10, 179-199.

Flavell, J. H. (1979). Metacognition and cognitive monitoring: A new era of cognitive-developmental inquiry. American Psychologist, 34(10), 906-911. http://dx.doi.org/10.1037/0003-066x.34.10.906

Geske, A., \& Ozola A. (2008). Factors influencing reading literacy at the primary school level. Problems of Education in the $21^{\text {st }}$ Century, 6, 71-77.

Guthrie, J. T., Wigfield, A., Humerick, N. M., Perencevich, K. C., Taboada, A., \& Barbosa, P. (2006). Influences of stimulating tasks on reading motivation and comprehension. The Journal of Educational Research, 99(4), 232-245. http://dx.doi.org/10.3200/JOER.99.4.232-246

Hermosa, N. (2002). The psychology of reading. Quezon City: University of the Philippines Open University.

Hong-Nam, K. \& Page, L. (2014). ELL high school students' metacognitive awareness of reading strategy use and reading proficiency. Teaching English as a Second or Foreign Language: The Electronic Journal for English as a Second Language, 18(1). Retrieved from http://www.tesl-ej.org/wordpress/issues/volume18/ ej69/ej69a4/

IELTS Partners (British Council, IDP: IELTS Australia Pty Ltd., and Cambridge English Language Assessment). (2015). IELTS Researchers: Test Taker Performance 2013. Retrieved from http://www.ielts.org/researchers/ analysis_of_test_data/test_taker_performance_2013.aspx

Ilustre, C. A. (2011).Beliefs about reading, metacognitive reading strategies and text comprehension among college students in a private university. Philippine ESL Journal, 7(July 2011), 28-47.

Ismail, N. M., \& Tawalbeh, T. I. (2015). Effectiveness of a metacognitive reading strategies program for improving low achieving EFL readers.International Education Studies, 8(1), 71-81.

Iwai, Y. (2011). The effects of metacognitive reading strategies: Pedagogical implications for EFL/ESL teachers. The Reading Matrix, 11(2), 150-157.

Jafari, S. M., \& Shokrpour, N. (2012). EAP students' reading motivation of English academic expository texts: A mixed methods design. International Journal of Linguistics, 4(4), 372-392. http://dx.doi.org/10.5296/ijl.v4i4.2459

Jamshidi, P., \& Moghaddam, M. Y. (2013). The effect of Iranian EFL learners' awareness of reading comprehension strategies on their motivation to read. International Journal of English Language Education, 1(1), 162-178. http://dx.doi.org/10.5296/ijele.v1i1.2995

Key, J. P. (1997). Research Design in Occupation Education. Oklahoma: Oklahoma State University. Retrieved from http://www.okstate.edu/ag/agedcm4h/academic/aged5980a/5980/newpage110.htm

Koda, K. (2007). Reading language learning: crosslinguistic constraints on second language reading development. Language Learning, 57(1), 1-44. http://dx.doi.org/10.1111/0023-8333.101997010-i1

Komiyama, R. (2013). Factors underlying second language reading motivation of adult EAP students. Reading in a Foreign Language, 25(2), 149-169.

Korotaeva, I. V. (2012). Metacognitive strategies in reading comprehension of education majors. Procedia Social and Behavioral Sciences, 69(2012), 1895-1900. http://dx.doi.org/10.1016/j.sbspro.2012.12.143

Kummin, S., \& Rahman, S. (2010). The relationship between the use of metacognitive strategies and achievement in English. Procedia - Social and Behavioral Sciences, 7, 145-150. http://dx.doi.org/10.1016/j.sbspro.2010.10.021

Louca, E. P. (2003). The concept and instruction of metacognition. Teacher Development, 7(1), 9-30. http://dx.doi.org/10.1080/13664530300200184

Maasum, T., \& Maarof, N. (2012). Empowering ESL readers with metacognitive reading strategies. Procedia Social and Behavioral Science, 69, 1250-1258. http://dx.doi.org/10.1016/j.sbspro.2012.12.058

Magogwe, J. M. (2013). Metacognitive awareness of reading strategies of University of Botswana English as a second language students of different academic reading proficiencies. Reading and Writing, 4(1), 1-8. Retrieved from http://dx.doi.org/10.4102/rw.v4i1.29 
Mehrdad, A. G., Ahghar, M. R., \& Ahghar, M. (2012). The effect of teaching cognitive and metacognitive strategies on EFL students' reading comprehension across proficiency levels. Procedia- Social and Behavioral Sciences, 46, 3757-3763. http://dx.doi.org/10.1016/j.sbspro.2012.06.142

Memis, A. \& Bozkurt, M. (2013). The relationship of reading comprehension success with metacognitive awareness, motivation, and reading levels of fifth grade students. Global Journal of Educational Foundation, 1(1), 034-038.

Mermelstein, A. D. (2014). Improving EFL learners' reading levels through extensive reading. The Reading Matrix, 14(2), 227-242.

Mitchel, M. L., \& Jolley, J. M. (2013). Research design explained. California: Cengage Learning.

Mokhtari, K., \&Sheorey, R. (2002). Measuring ESL students reading strategies. Journal of Developmental Education, 25(3), 2-10.

Mytcowicz, P., Goss, D., \& Steinberg, B. (2014). Assessing metacognition as a learning outcome in a postsecondary strategic learning course. Journal of Postsecondary Education and Disability, 27(1), 51-62.

National Center for Assessment in Higher Education: Department of Language Testing. (2011). Standardized Test of English Proficiency: A Guide for Students. Riyadh: National Center for Assessment in Higher Education. Retrieved from http://www.qiyas.sa/ApplicantsServices/publications/Docs/CurrentList /STEP\%20Standardized \%20Test\%20of\%20English\%20Proficiency.pdf

Nergis, A. (2013). Exploring the factors that affect reading comprehension of EAP learners. Journal of English for Academic Purposes, 12, 1-9. http://dx.doi.org/10.1016/j.jeap.2012.09.001

New South Wales Department of Education and Training. (2010). Teaching comprehension strategies: Curriculum K-12. New South Wales: NSW Department of Education and Training. Retrieved from http://www.curriculum support.education.nsw.gov.au/literacy/assets/pdf/packages/combook.pdf

Noursi, O. A. (2014). Teaching comprehension: What teachers should know? Perspectives (TESOL Arabia), 22(1), 11-22.

Pammu, A., Amir, Z., \&Maasum, T. (2014). Metacognitive reading strategies of less proficient tertiary learners: A case study of EFL learners at a public university in Makassar, Indonesia. Procedia - Social and behavioral Scences, 118, 357-364. http://dx.doi.org/10.1016/j.sbspro.2014.02.049

Pei, L. (2014). Does metacognitive strategy instruction indeed improve Chinese EFL learners' reading comprehension performance and metacognitive awareness? Journal of Language Teaching and Research, 5(5), 1147-1152. http://dx.doi.org/10.4304/j1tr.5.5.1147-1152

Perfetti, C. A., Landi, N., and Oakhill, J. (2004). The acquisition of reading comprehension skill. Retrieved from http://www.pitt.edu/ perfetti/PDF/The\%20Acquisition\%20of\%20Reading\%20Comprehension\%20Skill.pdf

Phakiti, A. (2006). Modeling cognitive and metacognitive strategies and their relationships to EFL reading test performance. Melbourne Papers in Language Testing, 1, 53-95.

Pierce, W. (2003). Metacognition: Study strategies, monitoring, and motivation. A workshop paper presented at Prince George's Community College. Retrieved from http://academic.pg.cc.md.us/ wpeirce/MCCCTR/ metacognition.htm\#V

Pintrich, R. R., Wolters, C. A., \& Baxter, G. P. (2000). Assessing metacognition and self-regulated learning. In G. Shraw, \& J. C. Impara (Eds.), Issues in the measurement of metacognition (pp. 43-97). Lincoln, NE: Buros Institute of Mental Measurements

Pitcher, S. M. (2007). Assessing Adolescents' Motivation to Read. Journal of Adolescent \& Adult Literacy, 50(5), 378-396. http://dx.doi.org/10.1598/JAAL.50.5.5

Pressly, M., Wharton-McDonald, R., Mistretta-Hampston, J., \& Echevarria, M. (1998). The nature of literacy instruction in ten grade - 4/5 classrooms in upstate New York. Scientific Studies of Reading, 2, 159-194. http://dx.doi.org/10.1207/s1532799xssr0202_4

Royanto, L. (2012). The effect of an intervention program based on scaffolding to improve metacognitive strategies in reading: A study of year 3 elementary school students in Jakarta. Procedia - Social and Behavioral Sciences, 69, 1601-1609

Rumerlhart, D. E. \& McClelland, J. L. (1981). Processing through spreading activation. In A. M. Lesgold, \& C. A. Perfetti (Eds) Interactive Processing in Reading (pp. 37-60). New Jersey: Lawrence Erlbaum. 
Sen, H. S. (2009). The relationship between the use of metacognitive strategies and reading comprehension. Procedia - Social and Behavioral Sciences, 1, 2301-2305. http://dx.doi.org/10.1016/j.sbspro. 2009.01.404

Tavakoli, H. (2014). The effectiveness of metacognitive strategy awareness in reading comprehension: The case of Iranian university EFL students. The Reading Matrix, 14(2), 314-336.

Trehearne, M. P., \& Doctorow, R. (2005). Reading comprehension: strategies that work. In Comprehensive Literacy Resource: Grade 3-6 (Chapter 2). Retrieved from https://www.hand2mind.com/pdf/miriam/ ch2_clr3_6.pdf

Yuksel, I., \&Yuksel, I. (2012). Metacognitive awareness of academic reading strategies.Procedia - Social and Behavioral Sciences, 31, 894-898. http://dx.doi.org/10.1016/j.sbspro.2011.12.164

Zhang, L., \& Seepho, S. (2013). Metacognitive strategy use and academic reading achievement: insights from a Chinese context. Electronic Journal of Foreign Language Teaching, 10(1), 54-69.

\section{Copyrights}

Copyright for this article is retained by the author(s), with first publication rights granted to the journal.

This is an open-access article distributed under the terms and conditions of the Creative Commons Attribution license (http://creativecommons.org/licenses/by/3.0/). 